\title{
María Dolores Bravo Arriaga. Panorama de textos novohispanos. Una antología. México: Universidad Autónoma de México, 2016.
}

Desde una perspectiva amplia e integradora, Dolores Bravo publica esta antología de textos novohispanos en la Biblioteca del estudiante universitario (BEU) de la Universidad Nacional Autónoma de México. Fundada en 1939, la BEU es una de las colecciones más antiguas y prestigiosas de la UNAM, que se define por su carácter antológico, fruto de la investigación, y su perfil divulgativo. De formato pequeño y con el propósito de abaratar costes y tener una amplia difusión, incluye en su catálogo obras de difícil acceso. Se ocupa de temas de literatura e historia mexicana, desde la época de la Conquista hasta el siglo xx, y su edición se confía a reconocidos especialistas.

En este marco editorial, Bravo se ocupa de trazar un panorama textual para la época colonial y declara, desde el principio, su voluntad de llevar a cabo una selección sugerente y atractiva para el lector actual. Los textos se ordenan cronológicamente en tres apartados por siglos: Siglo XVI, Siglo XVII y Siglo xviII. En cada capítulo, la editora se preocupa por buscar textos que, aunque sean desconocidos o poco accesibles, puedan dar cuenta del perfil característico y general de cada época. Además, en este esfuerzo por trazar el panorama novohispano de manera coherente, la investigadora no se limita a textos literarios sino que incluye también otros contenidos más heterogéneos, como fragmentos de diarios y gacetas, menologios, relaciones... que se alternan con sonetos, décimas y entremeses. El objetivo es, en este sentido, indicador del propósito abarcador de la antología y así lo expresa la propia autora: "para que los lectores reciban una serie de obras que les ofrezcan lo más revelador y completo de lo diverso y ambiguo de una sociedad compleja» (XIII). La misma heterogeneidad en la forma de los textos y los géneros en los que se inscriben aparece también en los contenidos, porque con la misma finalidad Dolores Bravo combina obras aparentemente opuestas y junta, en un significativo collage cultural, relaciones de fiesta, décimas a prostitutas y escritos conventuales.

Esta diversidad textual es uno de los primeros indicios que se ven reforzados por el título que preside la antología: panorama. Porque, efectivamente, este mosaico tan plural es el que da una idea de lo que, desde el principio de la colonia, supone para Nueva España trazar unos signos de identidad propios entre lo americano y lo peninsular. Otro de los rasgos que vienen marcados por el deseo de mostrar una panorámica textual novohispana es el carácter específico de cada uno de los apartados. A partir de un diseño general, con una nota que encabeza las ediciones, cada apartado recoge las muestras más características y predominantes en cada momento. Así, mientras la prosa sobre la ciudad de México es el común denominador del primer capítulo sobre el siglo XVI, el apartado sobre el siglo XVII es el más extenso y variado, sin un predominio claro de un género en particular y con cuatro subapartados (Vida conventual y religiosa; Biografías de carácter hagiográfico; Renacer del humanismo en el siglo XVII: la defensa del indígena y Relaciones de fiestas en verso y en prosa), $y$, en lo que respecta al apartado sobre el siglo XVIII, se aprecia una voluntad por ajustarse al espíritu ilustrado de la su ciudad letradaoder que ya definiera ia con la configuracigo de la se que se define claramente la conciencia criolla y surgenépoca, de ahí que destaquen textos sobre reglamentos urbanos y también de teatro. De ello pueden extraerse dos conclusiones. La primera reafirma que el siglo XVII tiene en Nueva España una especial vitalidad. Es, desde el punto de vista cultural y literario, el periodo central de la literatura novohispana, ya que a lo largo del siglo puede decirse que se define claramente una emergente conciencia criolla que, además, cristaliza en dos de los máximos escritores del periodo: Carlos de Sigüenza y Góngora y Sor Juana Inés de la Cruz. Esta afirmación sobre el decisivo papel del siglo XvII se confirma una vez 
más y certifica lo que ya probara la antología de Poetas novohispanos de Alfonso Méndez Plancarte, publicada entre 1942 y 1945 . La segunda conclusión que puede extraerse tiene que ver con el progresivo volumen y variedad de literatura impresa que se produce a lo largo de la época colonial y su directa correspondencia con la configuración de unas élites letradas. Son esos círculos de poder que ya definiera Ángel Rama en su ciudad letrada y que, efectivamente, son sintomáticos de la creciente vitalidad de la cultura impresa.
Desde esta perspectiva puede decirse que la antología de Dolores Bravo, escrita desde su generoso magisterio como investigadora y como docente, es un libro necesario para cualquier interesado en la cultura virreinal: es útil para todos aquellos que empiezan a adentrarse en su campo de estudio, a la vez que también resulta de lectura obligada para quienes se ocupan de su estudio en profundidad.

Judith FARré

Consejo Superior de Investigaciones Científicas 